\title{
Angiographic evidence for reduced graft patency due to competitive flow in composite arterial T-grafts
}

\author{
Dmitry Pevni, MD, ${ }^{a}$ Itzhak Hertz, MD, ${ }^{\mathrm{b}}$ Benjamin Medalion, MD, ${ }^{\mathrm{c}}$ Amir Kramer, MD, ${ }^{a}$ Yosef Paz, MD,
} Gideon Uretzky, MD, and Rephael Mohr, MD ${ }^{a}$

From the Departments of Cardiothoracic Surgery $^{\mathrm{a}}$ and Cardiology, ${ }^{\mathrm{b}}$ Tel Aviv Sourasky Medical Center and Departments of Cardiothoracic Surgery, Rabin Medical Center, ${ }^{\mathrm{c}}$ Faculty of Medicine, Tel Aviv University, Tel Aviv, Israel.

Received for publication July 18, 2005; revisions received July 7, 2006; accepted for publication July 17, 2006.

Address for reprints: R. Mohr, MD, Department of Cardiothoracic Surgery, Tel Aviv Sourasky Medical Center, 6 Weizman Street, Tel Aviv 64239, Israel (E-mail: marion@ tasmc.health.gov.il)

J Thorac Cardiovasc Surg 2007;133:1220-5 $0022-5223 / \$ 32.00$

Copyright () 2007 by The American Association for Thoracic Surgery

doi:10.1016/j.jtcvs.2006.07.060
Objective: Composite arterial grafting causes splitting of internal thoracic artery flow to various myocardial regions. The amount of flow supplying each region depends on the severity of coronary stenosis. Competitive flow in the native coronary artery can cause occlusion or severe narrowing of the internal thoracic artery supplying this coronary vessel.

Methods: Two hundred three consecutive postoperative coronary angiographies of 163 patients who underwent bilateral internal thoracic artery grafting using the composite-T-graft technique were analyzed. Angiographies were done in symptomatic patients or in patients with positive thalium scan between 2 and 102 months after surgery and were compared with preoperative angiograms.

Results: In 123 patients, both internal thoracic arteries were patent. The remaining 40 control patients had at least 1 nonfunctioning internal thoracic artery. A lower stenosis rate in the left anterior and circumflex arteries was associated with higher occlusion rate of the left internal thoracic artery $(P<.005)$ and the right internal thoracic artery $(P<.005)$, respectively. In 19 angiograms of 18 patients, graft failure could be related to competitive flow. This included 7 patients with disease of the left main artery and a preoperative stenosis degree ranging between 50\% and $80 \%, 8$ patients with moderate stenosis ( $70 \%$ or less) of the circumflex artery, and 3 with moderate stenosis of the left anterior descending artery. Three of the patients with disease of the left main artery, 2 of the patients with competitive flow in the circumflex artery, and all patients in the subgroup with left anterior descending arterial disease underwent percutaneous or surgical reintervention.

Conclusion: The composite T-graft technique of bilateral internal thoracic artery grafting should be reserved for patients with severe (70\% or more) left anterior descending and circumflex arterial stenosis.

卫 he use of both the left and right internal thoracic arteries (ITAs) for revascularization of the anterior descending and circumflex arteries has shown a decreased risk of death, need for reoperation, and need for percutaneous angioplastic reintervention when compared with revascularization using one ITA in combination with vein grafts. ${ }^{1-3}$ Several arrangements of bilateral ITA grafting have been proposed to achieve left anterior descending (LAD) and circumflex arterial grafting. A commonly used arrangement is the composite T-graft, ${ }^{4}$ whereby free ITA grafts (usually right ITA) are attached proximally end-to-side to in situ ITA (most often left ITA).

Studies using transit-time Doppler techniques indicate that construction of composite arterial grafts results in a significant increase in flow through the left ITA. However, conduit flow is largely affected by the native coronary flow. ${ }^{5,6}$ This observation must raise concern regarding residual graft flow in conduits used for grafting coronary arteries with noncritical stenosis. Indeed, in a recently published angiographic study of 362 patients with composite T-grafts, competitive flow was 


\section{Abbreviations and Acronyms \\ ITA $=$ internal thoracic artery \\ $\mathrm{LAD}=$ left anterior descending \\ SPECT $=$ single-photon emission computed tomography}

found in $14.6 \%$ of the composite grafts, and graft occlusion occurred in $3.6 \%$ of the patients. ${ }^{7}$

We started using the composite T-graft technique for bilateral ITA grafting in 1996; however, very few patients were elected to be studied after surgery. This report includes only ischemic (positive thalium scans) or symptomatic patients and is therefore meant to qualitatively describe angiographic findings suggesting competitive flow and not to accurately evaluate occurrence or prevalence of this phenomenon among patients with composite T-grafts.

\section{Materials and Methods}

Two hundred three consecutive postoperative coronary angiographies of 163 patients who underwent bilateral ITA grafting using the composite T-graft technique were performed between January 2000 and December 2004. ITAs were harvested as skeletonized vessels, ${ }^{8}$ and composite T-grafts were constructed using free ITA (mostly right ITA) attached end-to-side to in situ ITA (mostly left ITA). ${ }^{9}$

Coronary angiographies were performed between 2 months and 8.5 years postoperatively (mean $4.5 \pm 0.8$ years). During this period, 1150 consecutive patients underwent bilateral ITA grafting in our institute using the composite T-graft technique. All patients studied angiographically were evaluated because of angina recurrence or positive thalium single-photon emission computed tomography (SPECT) scintigraphy. In 123 patients, both ITAs were patent. The remaining 40 angiograms showed at least 1 nonfunctioning ITA. Postoperative angiographic studies were compared with preoperative angiograms to assess the relationship between preoperative noncritical coronary stenosis and ITA graft failure.
Competitive flow was suggested as the cause for nonfunctioning grafts to vessels with noncritical stenosis $(<70 \%)$, when grafts were occluded or severely stenotic (string sign) or not opacified during in situ ITA angiography but were demonstrated during contrast material injection into the native coronary tree. ${ }^{7}$

\section{Statistical Analysis}

Because the degree of coronary stenosis was not normally distributed, we initially used the nonparametric Kruskal-Wallis test to assess the effect of degree of coronary artery stenosis on left ITA and right ITA patencies. After noting that a lower degree of stenosis is associated with a higher occlusion rate, we decided to categorize the degree of stenosis in each coronary vessel for further analysis. After several trials, it seemed that categorizing the stenosis into $<50 \%$, between $50 \%$ and $70 \%$, and $>70 \%$ best described the data.

\section{Results}

The frequency of each stenosis category for each coronary vessel and the respective left ITA and right ITA patencies are shown in Table 1. A univariable Kruskal-Wallis test identified that lower stenosis rates in the LAD are associated with higher rates of left ITA occlusion $(P<.005)$. The lower stenosis rate in the circumflex artery was found to be associated with right ITA occlusion $(P<.005)$. The severity of left main artery stenosis did not affect left ITA or right ITA patency $(P=.569)$.

In 18 patients (19 angiograms - 1 patient was studied twice), postoperative ITA graft failure could be related to competitive flow.

\section{Left Main Arterial Disease}

Seven $(39 \%)$ of the 18 patients with competitive flow were referred for surgery because of disease of the left main artery (Table 2, patients 1-7). Occurrence of competitive flow in postoperative angiograms of patients with disease of the left main artery (7 of 30) was significantly higher than

TABLE 1. Frequency of each stenosis category for each coronary vessel and the respective LITA and RITA patencies

\begin{tabular}{|c|c|c|c|c|c|c|c|c|c|}
\hline \multicolumn{4}{|c|}{ LITA } & \multicolumn{4}{|c|}{ RITA } & & \\
\hline \multicolumn{2}{|c|}{ Occluded } & \multicolumn{2}{|c|}{ Patent } & \multicolumn{2}{|c|}{ Occluded } & \multicolumn{2}{|c|}{ Patent } & & \\
\hline Row N (\%) & Count & Row N (\%) & Count & Row N (\%) & Count & Row N (\%) & Count & \multicolumn{2}{|c|}{$\%$ stenosis } \\
\hline 15.8 & 21 & 84.2 & 112 & 19.5 & 26 & 80.5 & 107 & $\leq 50$ & LM \\
\hline 20.0 & 3 & 80.0 & 12 & 6.7 & 1 & 93.3 & 14 & $51-70$ & \\
\hline 0 & 0 & 100.0 & 15 & 13.3 & 2 & 86.7 & 13 & $71+$ & \\
\hline 44.4 & 12 & 55.6 & 15 & 25.9 & 7 & 74.1 & 20 & $\leq 50$ & LAD \\
\hline 28.6 & 6 & 71.4 & 15 & 23.8 & 5 & 76.2 & 16 & $51-70$ & \\
\hline 5.2 & 6 & 94.8 & 109 & 14.8 & 17 & 85.2 & 98 & $71+$ & \\
\hline 22.7 & 5 & 77.3 & 17 & 50.0 & 11 & 50.0 & 11 & $\leq 50$ & LCX \\
\hline 24.1 & 7 & 75.9 & 22 & 34.5 & 10 & 65.5 & 19 & $51-70$ & \\
\hline 10.7 & 12 & 89.3 & 100 & 7.1 & 8 & 92.9 & 104 & $71+$ & \\
\hline
\end{tabular}

LITA, Left internal thoracic artery; RITA, right internal thoracic artery; $L A D$, left anterior descending; $L C X$, left circumflex artery; $L M$, left main artery. 
TABLE 2. Relation between proximal stenosis site and \% stenosis to graft patency in composite T-grafts

\begin{tabular}{|c|c|c|c|}
\hline Patient No. & Site of proximal stenosis (\%) & Patent graft & Failed graft (\%) \\
\hline 1 & Lt. main 50 & - & LITA to LAD (OC) RITA to OM1 (OC) \\
\hline 2 & Lt. main 80 & - & LITA to LAD (OC) RITA to OM2 (OC) \\
\hline 3 & Lt. main 85 & RITA to Diag + Marg & LITA to LAD (OC) \\
\hline 4 & Lt. main $50, \mathrm{Cx} 70$ & RITA to $\mathrm{Cx}$ & LITA to $\operatorname{LAD}(O C)$ \\
\hline 5 & Lt. main 60, Cx 75 & RITA to $C x$ & LITA to LAD (OC) \\
\hline 6 & Lt. main 70, CX 90, 0M 80 & RITA to $\mathrm{Cx}$ & LITA to LAD (STR) \\
\hline 7 & Lt. main 80, Cx 75, Diag 80 & RITA to Diag and $C x$ & LITA to LAD (OC) \\
\hline 8 & LAD 60, Cx 90 & RITA to $\mathrm{Cx}$ & LITA to LAD (OC) \\
\hline 9 & LAD 65, Cx 90 & RITA to Diag-Cx & LITA to LAD (OC) \\
\hline 10 & LAD 40, Cx 90 & RITA to $C x$ and PDA & LITA to LAD (OC) \\
\hline 11 & LAD 80, Cx 60, Prox. RCA 70 & LITA to LAD, RITA to $C x$ & Segment of RITA between OM1 and PDA (NFG) \\
\hline 12 & LAD 100, Diag 80, Cx 50 & LITA to LAD, RITA to Diag & Segment of RITA between Diag and OM2 (OC) \\
\hline 13 & LAD 90, Cx 70 & $\begin{array}{l}\text { LITA to LAD, segment of RITA between } \\
\text { OM1-OM2 }\end{array}$ & RITA to OM1 (OC) \\
\hline 14 & LAD 85, Cx 70 & LITA to LAD-Diag. & RITA to $\mathrm{Cx}(\mathrm{OC})$ \\
\hline 15 & LAD 80, Cx 60, RCA 100 & LITA to LAD-Diag & RITA to $C x$ and PDA (OC) \\
\hline 16 & LAD 85, Cx 70, $0 \mathrm{M} 385$ & LITA to LAD-Diag & RITA to OM1 + OM2 (OC) \\
\hline 17 & LAD 100, Cx 70 & LITA to LAD & RITA to OM1 (OC) \\
\hline 18 & LAD 80, Cx 50, PDA 90 & LITA to LAD (RITA bridge from OM2-PDA) & RITA to OM2 (STR) \\
\hline 18 (1 y later) & LAD 90, Cx 100 & LITA to LAD, RITA to M2 + PDA & - \\
\hline
\end{tabular}

that in angiograms of patients without the disease (11 of 133, $P<.02$; Table 1). Three had ostial lesions with ventricularization of pressure during ostial left main artery intubation. In this subgroup, assessment of ostial stenosis is problematic even with multiple views. In 2 of these 3, both limbs of the composite T-graft were occluded, and in the third, left ITA to LAD was occluded and the segment of right ITA to circumflex marginal was slightly narrowed. The right ITA could be demonstrated both during native left coronary artery injection and during injection of contrast material into the ostium of the left ITA.

Two other patients with $50 \%$ and $60 \%$ left main arterial stenosis had moderate stenosis in circumflex and mild LAD arterial stenosis. Both had complete occlusion of the left ITA to LAD limb of the composite T-graft (Figure 1). However, thalium SPECT did not show any sign of ischemic changes at the anterior and septal regions of the heart, suggesting competitive flow as the cause of distal left ITA occlusion.

The last 2 patients with disease of the left main artery had $80 \%$ and $70 \%$ stenosis of their left main artery without severe lesions in the LAD. One had occlusion of the left ITA graft to the LAD; however, the LAD was opacified during injection to the native left system and was also filled retrogradely through the circumflex that was well demonstrated during injection to the proximal left ITA and right ITA (Figure 2). Additionally, this patient did not have any signs of anterior wall ischemia in thalium SPECT scintigraphy. In the second patient with moderate circumflex arterial stenosis, the distal left ITA was occluded and the LAD was filled retrogradely through the diagonal artery that was the first and most proximal sequential anastomosis of the right ITA. Three of the 7 patients with disease of the left main artery with competitive flow had to undergo reintervention.

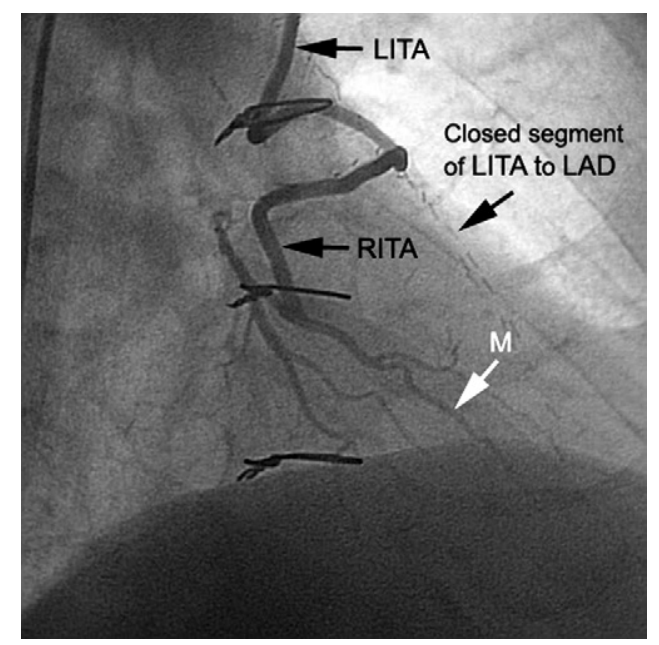

Figure 1. Patient 5-left main arterial disease. Influence of competitive flow of left ITA graft to the LAD. Injection to the ITA. ITA, Internal thoracic artery; $L A D$, left anterior descending. 

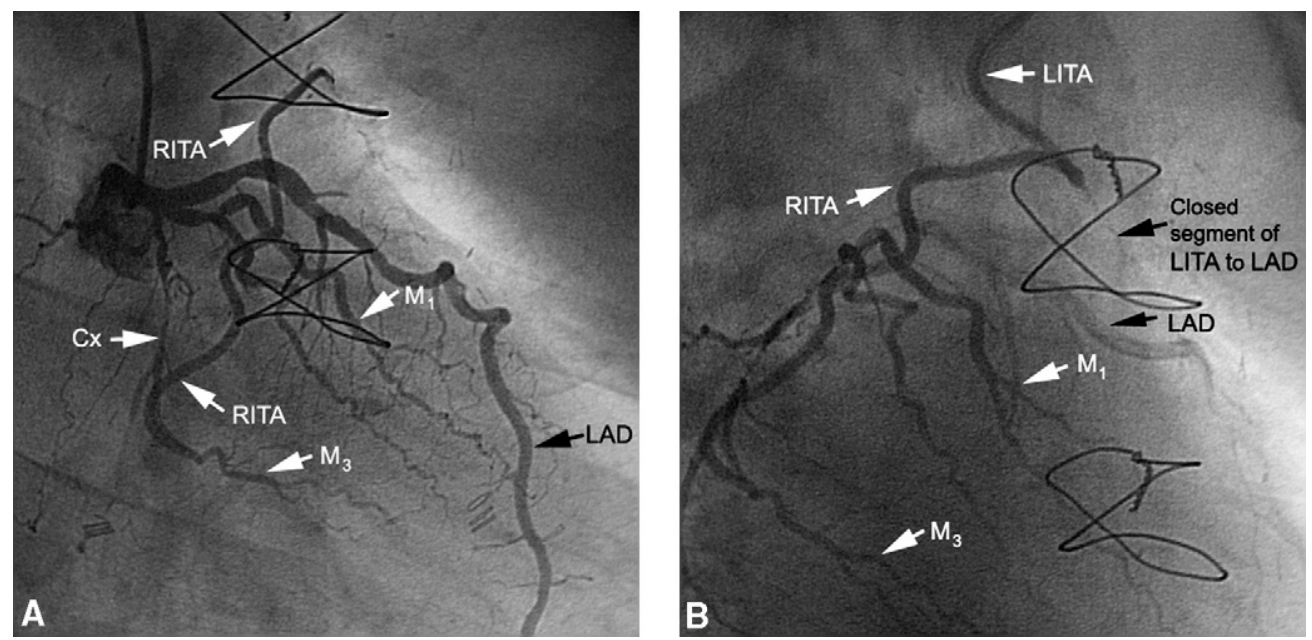

Figure 2. Patient 6 -left main disease. A, Injection to the native left coronary system. $B$, Injection to the left ITA. RITA, right internal thoracic artery; $L A D$, left anterior descending; LITA, left internal thoracic artery.
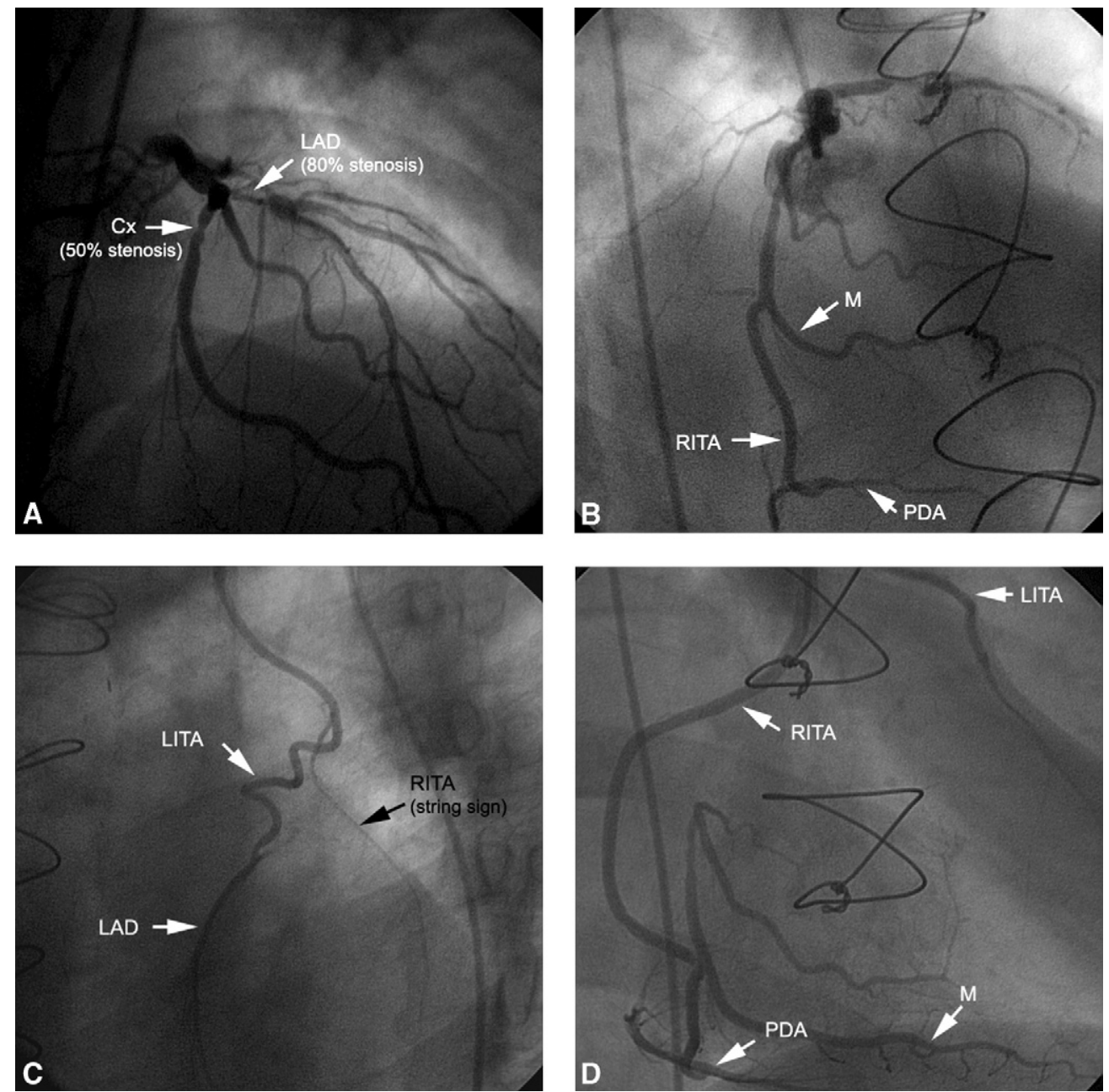

Figure 3. Influence of competitive flow on patency of right ITA connected to marginal branch of the circumflex (patient 18). A, Preoperative coronary angiogram. B, Injection to the left coronary system (1 year after surgery). $C$, Injection to the left ITA (1 year after surgery). D, Injection to the left ITA (2 years postoperatively). ITA, internal thoracic artery. 

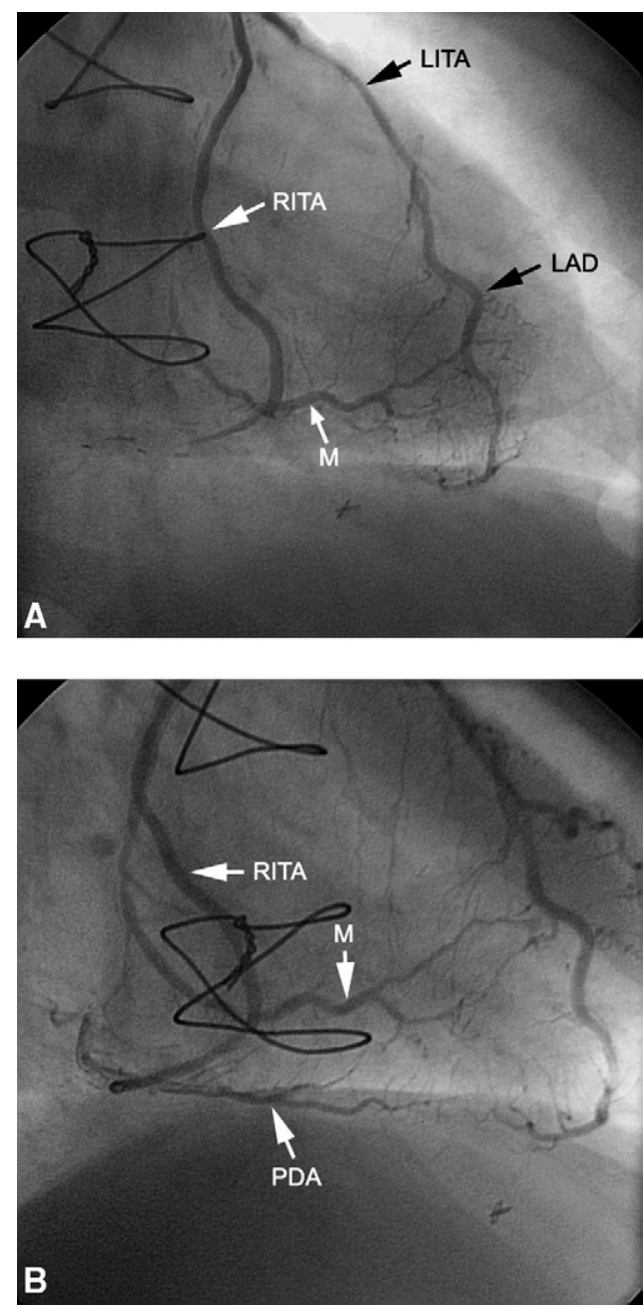

Figure 4. Competitive flow between the right system (PDA) and the distal segment of the free right ITA between marginal branch (M) and PDA (patient 11). A, Normal injection to the left ITA. $B$, Forced injection to the left ITA. ITA, Internal thoracic artery; $P D A$, posterior descending artery.

Competitive Flow in the Circumflex Arterial Territory In 8 patients (Table 2, patients 11-18), left ITA to LAD was patent; however, the right ITA limb of the composite T-graft was severely narrowed (string sign; Figure 3,C) or was occluded and could not be demonstrated during injection to the left ITA. In some cases, patent segments between the various sequential anastomoses could be demonstrated during contrast material injection into the native coronary arteries (Figure 3, B). In 2 of these patients, forced injection to the left ITA enabled demonstration of the whole length of the right ITA (Figure 4). String sign due to competitive flow can reopen with progression of native coronary artery stenosis (Figure 3,D). Two patients with competitive flow in the circumflex-right coronary artery regions underwent reintervention.
Segments of the right ITA that can be demonstrated during injection to the native coronary artery may disappear after dilatation of stenotic coronary lesions during percutaneous interventions.

\section{Competitive Flow in the LAD Arterial Territory}

In 3 patients with $<70 \%$ stenosis of the LAD (Table 2, patients $8-10$ ), postoperative angiography did not demonstrate the distal left ITA limb to the LAD. All 3 were referred for coronary angiography $(1,3$, and 5 years postoperatively) due to recurrent angina and ischemic changes in the anterior wall of the heart (positive thalium SPECT scan). Postoperative angiography demonstrated progression of their native LAD disease and significant LAD stenosis, necessitating reintervention.

\section{Discussion}

Left-sided bilateral ITA grafting can be regarded as the best surgical revascularization technique with respect to survival and freedom from adverse cardiovascular events such as late myocardial infarction, recurrent angina, and reintervention. ${ }^{1,2,10}$ With the advent and increased popularity of the off-pump technique, many surgeons currently use the technique of arterial composite $\mathrm{T}$ - or Y-grafting with free right ITA or radial artery attached end-to-side to the left ITA. ${ }^{5,7,11-16}$ This arrangement enables performance of complete arterial myocardial revascularization with aorta notouch technique, thus decreasing aortic manipulation with its associated risk of stroke due to dislodgment of calcific or atherosclerotic particles from the aortic wall. ${ }^{17}$

The findings of the current study are based on a relatively long period of routine use of this surgical technique in more than $50 \%$ of the patients referred for bypass surgery in our institute and other institutes in our region.

The main purpose of this report is to avoid routine use of this grafting technique by adding a word of caution regarding the relatively frequent findings of competitive flow in postoperative coronary angiographies of patients with recurrent angina or positive stress test. Of major concern is the subgroup of patients with disease of the left main artery (even those with $80 \%$ stenosis) or a moderate degree of stenosis in their LAD.

Surgical revascularization is purported to improve patients' survival, which is largely dependent on patent ITA graft to the LAD. Failure of ITA graft to LAD as a result of competitive flow deprives the patient of the main benefit he or she expected to gain from the operation that could have been achieved by using a simple in situ ITA (left or right). ${ }^{18}$ In a recently published report by Sabik and colleagues, ${ }^{19}$ multivariable analysis identified the degree of preoperative proximal coronary stenosis (a surrogate of competitive flow) to be an important predictor of ITA graft occlusion. However, even in vessels with a stenosis degree as low as 
$50 \%$, the patency rate of in situ ITA to LAD was over $90 \%$. This excellent patency of in situ ITA to LAD was longlasting and remained high up to 15 years or more after surgery. ${ }^{19}$ We therefore think that composite T- or Ygrafting with two ITAs should be reserved for patients with severe stenoses in their LAD and marginal branches of the circumflex. Other grafting arrangements using two in situ ITA grafts such as anteaortic $\mathrm{cross}^{4}$ or retroaortic right ITA routing ${ }^{20}$ should be considered or even preferred in patients with disease of the left main artery or patients with moderate stenosis in the LAD and circumflex arteries. Shah and colleagues $^{21}$ found that proximal anastomosis of the right ITA to the aorta negated the significant patency loss associated with bypassing coronaries with $<80 \%$ stenosis. In these patients, aortocoronary grafting with free ITA may be preferred over the composite T-graft technique.

\section{Conclusions}

The data presented in the present study suggest that a higher stenosis rate is associated with better patency. However, our data did not provide enough evidence to show that the T-graft technique itself affects graft patency.

There is no way this study can accurately estimate occurrence of graft failure among patients with bilateral ITA grafting and the composite T-graft arrangement because of the following reasons:

1. Only symptomatic patients or patients with positive thalium scans were studied angiographically. The selection of these subgroups of patients who are more likely to have failed grafts causes underestimation of true graft patency.

2. Full angiographic data were available only during the years 2000 to 2004. A relatively large number of angiographic studies of patients operated on before the year 2000 were not available for evaluation.

3. The composite T-graft technique is very popular today in other centers in our region, and $>10 \%$ of the patients studied (including 4 of the 18 with results compatible with competitive flow) were operated on outside our institute. Similarly, one may assume that some of our patients were studied angiographically elsewhere.

4. Other factors may have played a role in some of the reported graft failures, such as distal anastomotic technical problems, technical problems in the composite $\mathrm{T}$ anastomosis, poor distal runoff, and collateral blood flow from other coronary arteries.

\section{References}

1. Lytle BW, Blackstone EH, Loop FD, et al. Two internal thoracic artery grafts are better than one. J Thorac Cardiovasc Surg. 1999;117:855-72.
2. Buxton BF, Komeda M, Fuller JA, Gordon I. Bilateral internal thoracic artery grafting may improve outcome of coronary artery surgery. Risk-adjusted survival. Circulation. 1998;98:II1-6.

3. Schmidt SE, Jones JW, Thornby H, Miller CC, Beall AC. Improved survival with multiple left-sided bilateral internal thoracic artery grafts. Ann Thorac Surg. 1997;64:9-14.

4. Lev-Ran O, Paz Y, Pevni D, et al. Bilateral internal thoracic artery grafting: midterm results of composite versus in situ crossover graft. Ann Thorac Surg. 2002;74:704-11.

5. Royse AG, Royse CF, Groves KL, Yu G. Blood flow in composite arterial grafts and effect of native coronary flow. Ann Thorac Surg. 1999;68:1619-22.

6. Markwirth T, Hennen B, Scheller B, Schaefers HJ, Wendler O. Flow wire measurements after complete arterial coronary revascularization with T-grafts. Ann Thorac Surg. 2001;71:788-93.

7. Nakajima H, Kobayashi J, Tagusari O, Bando K, Niwaya K, Kitamura $S$. Competitive flow in arterial composite grafts and effect of graft arrangement in off-pump coronary revascularization. Ann Thorac Surg. 2004;78:481-6.

8. Cunningham JM, Gharavi MA, Fardin R, Meek RA. Considerations in the skeletonization technique of internal mammary artery dissection. Ann Thorac Surg. 1992;54:947-50.

9. Pevni D, Mohr R, Lev-Ran O, et al. Technical aspects of composite arterial grafting with double skeletonized internal thoracic arteries. Chest. 2003;123:1348-54.

10. Pick AW, Orszulak TA, Anderson B, Schaff HV. Single versus bilateral internal mammary artery grafts: 10-year outcome analysis. Ann Thorac Surg. 1997;64:599-605.

11. Calafiore AM, Di Mauro M, D’Alessandro S, et al. Revascularization of the lateral wall: long term angiographic and clinical results of radial artery versus right internal thoracic artery grafting. $J$ Thorac Cardiovasc Surg. 2002;123:225-31.

12. Wendler $\mathrm{O}$, Hennen $\mathrm{B}$, Markwirth $\mathrm{T}$, et al. $\mathrm{T}$ grafts with the right internal thoracic artery to left internal thoracic artery versus the left internal thoracic artery and radial artery: flow dynamics in the internal thoracic artery main stem. J Thorac Cardiovasc Surg. 1999;118:841-8.

13. El Nakadi B, Choghari C, Joris M. Complete myocardial revascularization with bilateral internal thoracic artery T graft. Ann Thorac Surg. 2000;69:498-500.

14. Bonacchi M, Prifti E, Giunti G, Salica A. Right Y-graft, a new surgical technique using mammary arteries for total myocardial revascularization. Ann Thorac Surg. 2000;70:820-3.

15. Barner HB. The continuing evolution of arterial conduits. Ann Thorac Surg. 1999;68:S1-S8.

16. Maniar HS, Barner HB, Bailey MS, et al. Radial artery patency: are aortocoronary conduits superior to composite grafting? Ann Thorac Surg. 2003;76:1498-504.

17. Lev-Ran O, Braunstein R, Sharony R, et al. No-touch aorta off-pump coronary surgery: the effect on stroke. J Thorac Cardiovasc Surg. 2005; 129:307-13.

18. Dion R, Etienne PY, Verhelst R, et al. Bilateral mammary grafting. Eur J Cardiothorac Surg. 1993;7:287-94.

19. Sabik JF III, Lytle BW, Blackstone EH, Khan M, Houghtaling PL, Cosgrove DM. Does competitive flow reduce internal thoracic artery graft patency? Ann Thorac Surg. 2003;76:1490-7.

20. Ura M, Sakata R, Nakayama Y, Arai Y, Oshima S, Noda K. Analysis by early angiography of right internal thoracic artery grafting via the transverse sinus: predictors of graft failure. Circulation. 2000;101: 640-6.

21. Shah PJ, Durairaj M, Gordon I, Fuller J, Rosalion A, Seevanayagam S, et al. Factors affecting patency of internal thoracic artery graft: clinical and angiographic study in 1434 symptomatic patients operated between 1982 and 2002. Eur J Cardiothorac Surg. 2004; 26:118-24. 